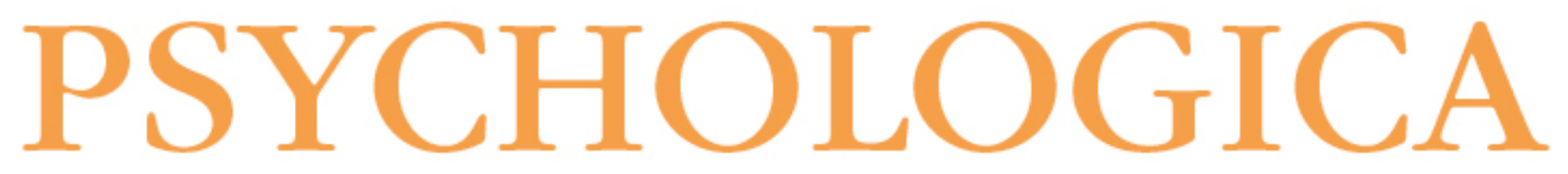

\title{
Crenças e atitudes de estudantes do ensino superior associadas ao uso de substâncias psicoativas
}

\author{
Autor(es): $\quad$ Costa, Maria Beatriz; Martins, Maria José D.; Proença, Adelaide João; \\ Silva, Ana Mateus
}

Publicado por: Imprensa da Universidade de Coimbra

URL

persistente: URI:http://hdl.handle.net/10316.2/42345

DOI: DOI:https://doi.org/10.14195/1647-8606_60-1_2

Accessed : $\quad$ 26-Apr-2023 01:05:57

A navegação consulta e descarregamento dos títulos inseridos nas Bibliotecas Digitais UC Digitalis, UC Pombalina e UC Impactum, pressupõem a aceitação plena e sem reservas dos Termos e Condições de Uso destas Bibliotecas Digitais, disponíveis em https://digitalis.uc.pt/pt-pt/termos.

Conforme exposto nos referidos Termos e Condições de Uso, o descarregamento de títulos de acesso restrito requer uma licença válida de autorização devendo o utilizador aceder ao(s) documento(s) a partir de um endereço de IP da instituição detentora da supramencionada licença.

Ao utilizador é apenas permitido o descarregamento para uso pessoal, pelo que o emprego do(s) título(s) descarregado(s) para outro fim, designadamente comercial, carece de autorização do respetivo autor ou editor da obra.

Na medida em que todas as obras da UC Digitalis se encontram protegidas pelo Código do Direito de Autor e Direitos Conexos e demais legislação aplicável, toda a cópia, parcial ou total, deste documento, nos casos em que é legalmente admitida, deverá conter ou fazer-se acompanhar por este aviso.

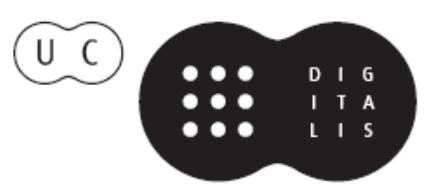


vOLUME
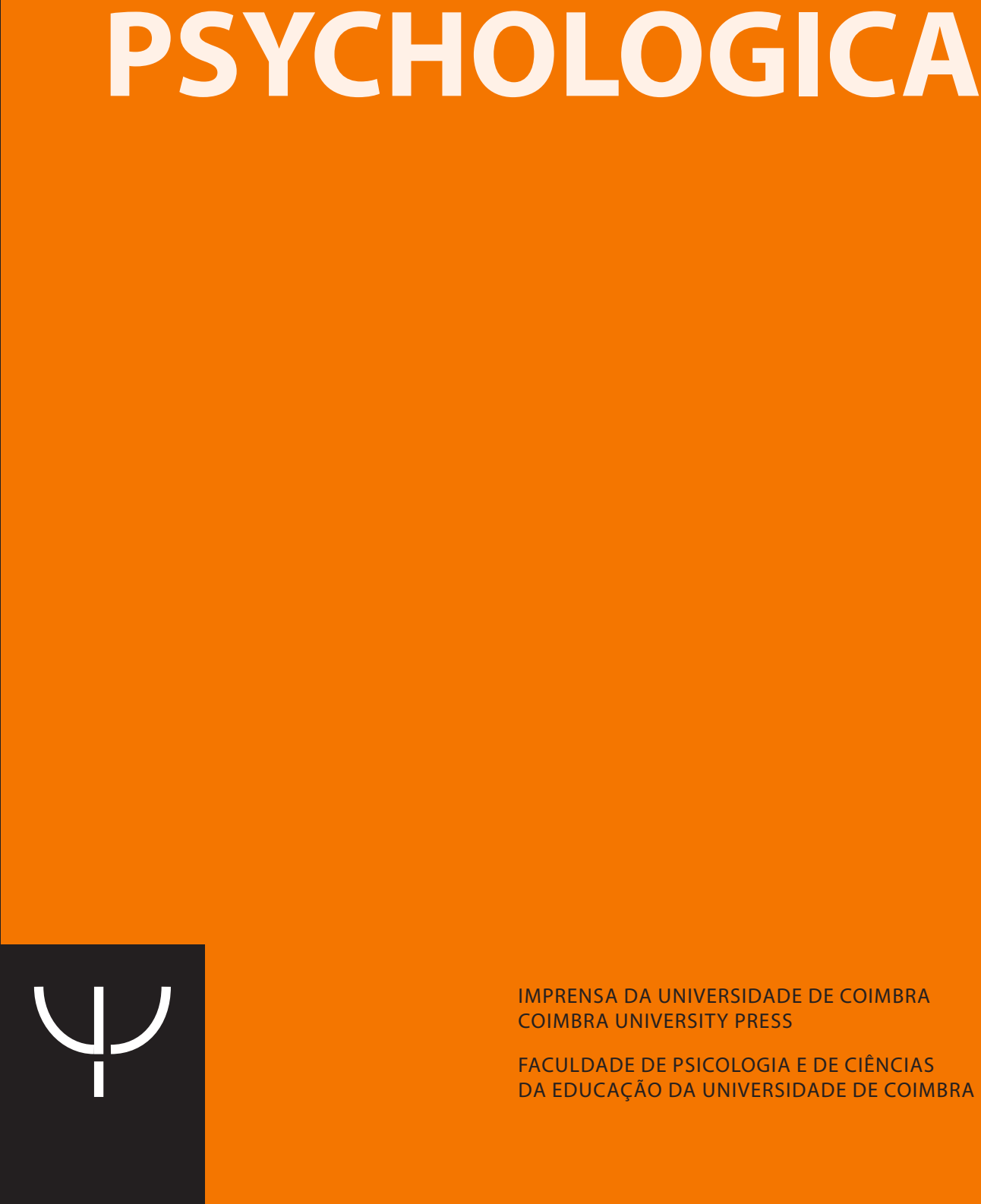

IMPRENSA DA UNIVERSIDADE DE COIMBRA

COIMBRA UNIVERSITY PRESS

FACULDADE DE PSICOLOGIA E DE CIÊNCIAS

DA EDUCAÇÃO DA UNIVERSIDADE DE COIMBRA 


\title{
Crenças e atitudes de estudantes do ensino superior associadas ao uso de substâncias psicoativas
}

\author{
Maria Beatriz Costa ${ }^{1}$, Maria José D. Martins ${ }^{2}$, \\ Adelaide João Proença ${ }^{3}$ e Ana Mateus Silva ${ }^{4}$
}

Beliefs and attitudes of higher education students associated with the use of psychoactive substances

\begin{abstract}
The entry in a higher education institution enables young people to new experiences, some contribute to their development, others can be harmful to their health. The main objectives of this study were to examine the type and frequency of legal and illegal psychoactive substances, used by students of polytechnics, and their beliefs and attitudes or cognitive distortions associated with these consumptions. We adapted the HIT-D\&A questionnaire (How I Think about Drugs and Questionnaire Alcohol) from Barriga and colleagues (2008) and applied it to 193 students, aged between 19 and 25 and attending the first year of a higher education course. The results showed that the most consumed psychoactive substances were alcohol, followed by tobacco and then marijuana. The results are discussed in terms of the role of the irrational beliefs in behaviour with consequences for human health and the most appropriate strategies to prevent the use of these substances.
\end{abstract}

Keywords: psychoactive substances; irrational beliefs; students

1 Escola Superior de Educação e Ciências Sociais do Instituto Politécnico de Portalegre, Portugal. Email: mi.beatriz.costa@gmail.com

2 Escola Superior de Educação e Ciências Sociais do Instituto Politécnico de Portalegre, Portugal; UIDEF-IEUL. Email: mariajmartins@esep.pt

3 Escola Superior de Educação e Ciências Sociais do Instituto Politécnico de Portalegre, Portugal. Email: adelaideproenca@esep.pt

4 Investigadora integrada do Centro de Estudos das Migrações e das Relações Interculturais (CEMRI), Portugal. Email: aisilva@cemri.uab.pt

Artigo recebido a 23-02-2015 e aprovado a 20-09-2016.

PSYCHOLOGICA VOLUME 60 № $1 \cdot 2017$ 


\section{Resumo}

A entrada no ensino superior permite aos jovens experienciar novas vivências, umas contribuem para o seu desenvolvimento, outras podem ser prejudiciais à saúde. Os principais objetivos deste estudo foram: conhecer o tipo e a frequência de substâncias psicoativas legais e ilegais, usadas pelos estudantes do ensino superior politécnico, e as crenças e atitudes ou distorções cognitivas associadas a esses consumos. Adaptou-se o questionário HIT-D\&A (How I Think about Drugs and Alcool Questionnaire) de Barriga e colaboradores (2008) e aplicou-se a 193 estudantes, com idades entre os 19 e os 25 anos do primeiro ano do ensino superior. Os resultados permitem concluir que as substâncias psicoativas mais consumidas foram o álcool, seguido do tabaco, e depois da marijuana. Os resultados são discutidos em termos do papel das crenças irracionais nos comportamentos com consequências na saúde e das estratégias mais adequadas para prevenir o consumo destas substâncias.

Palavras-chave: substâncias psicoativas; crenças irracionais; estudantes

\section{INTRODUÇÃO}

O primeiro ano de frequência do ensino superior é um ano de novas experiências, novas amizades e de adaptação a um novo meio. Vários autores consideram que a adolescência nas sociedades ocidentais tem vindo a prolongar-se para lá dos 18 anos (Eisenstein, 2005) e alguns autores (Sprinthall \& Collins, 1994) têm vindo a sugerir uma nova etapa denominada de juventude para caraterizar o período dos 18 aos 25 anos, enfatizando as suas similitudes com a fase da adolescência mas já sem o impacto das transformações fisiológicas. Esta etapa da vida é frequentemente um período de desenvolvimento feliz e saudável, mas pode ser também um período de vulnerabilidade na qual se fazem experiências ou se aumentam os consumos regulares de substâncias psicoativas legais e ilegais.

Segundo Patrício (2006, p. 79), “uma substância é psicoativa quando, após ter sido absorvida, modifica o funcionamento mental do consumidor, porque interfere sobre os mecanismos bioquímicos cerebrais". O autor explica que as substâncias psicoativas podem alterar as funções do cérebro de três formas diferentes: podem provocar efeitos de excitação, sedação ou perturbação. Podem ter interferência com o sono, a atenção e ao nível da memória. Podem também mudar a forma e o conteúdo do pensamento. E podem ainda criar modificações ao nível da sensibilidade, da fala e do andar. $\mathrm{O}$ autor defende ainda que, dependendo do seu uso, as substâncias psicoativas podem ser prejudiciais para a saúde (Patrício, 2006). 
De acordo com Patrício $(2002,2006)$ as consequências para a saúde do consumo de substâncias psicoativas dependem do tipo de substância e do tipo de consumo associado. Assim, podem considerar-se seis etapas no percurso do consumo de substâncias psicoativas: primeiro contato, experimentação ocasional, consumo regular, consumo excessivo, dependência e quadro aditivo. Todas as fases acarretam problemas, no entanto os riscos tendem a aumentar ao longo do processo (Ministério da Educação - Projeto Vida, 1988).

Em Portugal, têm sido desenvolvidos vários estudos sobre os consumos de substâncias realizados em meio escolar, destacando-se o Estudo sobre o Consumo de Álcool, Tabaco e Drogas [ECATD], que faz parte do European School Survey on Alcohol and other Drugs (Feijão, Lavado, \& Calado, 2011). Trata-se de um estudo realizado a nível europeu que conta com a participação de 35 países. O estudo realiza-se desde 1995 com a periodicidade de quatro anos e destina-se a acompanhar a evolução dos consumos de substâncias psicoativas pelos alunos de 16 anos, a nível europeu. A partir de 2003, em Portugal alargou-se a amostras representativas de alunos de cada um dos grupos etários dos 13 aos 18 anos. As conclusões do ECATD do ano de 2011 relativos a Portugal, no que concerne aos consumos de álcool, apontam para um decréscimo de 2007 a 2011, na percentagem de experimentação, em todos os grupos etários, de uma forma global e de modo semelhante nos rapazes e nas raparigas (37\% aos 13 anos e os $91 \%$ aos 18 anos). Conclui-se ter havido um decréscimo igualmente na percentagem de consumidores atuais (últimos 30 dias), em todos os grupos etários, globalmente e de modo semelhante nos rapazes e nas raparigas (13\% aos 13 anos e $70 \%$ aos 18 anos) (Feijão et al., 2011).

No entanto, os dados apontam também para um aumento das percentagens de alunos que já se embriagaram, e dos que o fizeram nos 30 dias antes do estudo, a partir do grupo etário dos 15 anos, sendo os aumentos mais acentuados para as raparigas. Já as prevalências de embriaguez ao longo da vida situam-se entre os $8 \%$ aos 13 anos e os 54\% aos 18 anos e, nos últimos 30 dias, antes do estudo, entre os $2 \%$ aos 13 anos e os $23 \%$ aos 18 anos. Nesta categoria, um destaque ainda para um aumento da frequência dos episódios de embriaguez, em todos os grupos etários e em ambos os sexos, sendo mais acentuada a partir dos 15 anos (Feijão et al., 2011).

Associados aos consumos, existem frequentemente crenças irracionais que valorizam o prazer imediato obtido pelos consumos, desvalorizam ou minimizam os danos na saúde e justificam os consumos através de processos de desresponsabilização e culpabilização dos outros por esses comportamentos. Em Portugal, vários estudos indicam um aumento dos consumos de tabaco e álcool no ensino superior e, em particular, um consumo abusivo do álcool durante as praxes académicas (e.g., Cabral, 2007; Pimentel, Mata, \& Anes, 2013). 
Um estudo de Zeferino e colaboradores (2015) com 250 estudantes universitários brasileiros identifica o álcool e o tabaco como as substâncias psicoativas mais consumidas pelos estudantes do ensino superior e destaca o papel dos pares como principal fator de risco dos consumos.

Uma investigação recente sobre consumo de substâncias psicoativas em estudantes da Universidade de Lisboa (Alcantara et al., 2015), com uma amostra de 3327 estudantes de vários cursos, revelou que as crenças sobre a perceção de risco influenciam a probabilidade de consumir substâncias psicoativas lícitas ou ilícitas, que os estudantes de ensino superior exibem uma elevada prevalência de consumo de álcool e de estados de embriaguez, quando comparados com os resultados obtidos com a população geral (80.9\% do sexo masculino e $68.6 \%$ do sexo feminino havia consumido álcool nos últimos 30 dias). Os referidos autores concluíram que os consumos de todas as substâncias psicoativas consideradas (tabaco, café, álcool, e várias substâncias psicoativas ilícitas) eram mais frequentes: nos estudantes mais novos do ensino superior, quando comparados com os mais velhos; e no sexo masculino quando comparado com o sexo feminino, excepto no que se referia aos medicamentos não prescritos, em particular os tranquilizantes, que eram mais consumidos pelo sexo feminino. Os consumos eram mais frequentes nos estudantes que não residiam com os pais e associavam-se mais à participação em eventos de convívio com os pares e de festas, verificando-se que as crenças que associavam o consumo das referidas substâncias à diversão, experimentação, liberdade, e a um estilo de vida que envolvia correr maiores riscos e menor cuidado pessoal, se associavam a uma maior probabilidade de consumos das várias substâncias psicoativas, com destaque para o álcool (Alcantara et al., 2015).

O papel das distorções cognitivas no comportamento, também designadas por crenças irracionais ou erros de pensamento, tem sido estudado sobretudo em associação com as condutas agressivas e delinquentes (Gibbs, Potter, \& Goldstein, 1995; Martins, 2009; Martins \& Vicente Castro, 2007).

Vários autores (Dibiase, Gibbs, Potter, \& Bount, 2012; Gibbs, 1991 citado em Martins, 2009; Martins \& Casasnovas, 2014) sugerem que se considerem as seguintes distorções cognitivas:

- Centração no eu - Pensar que as suas opiniões e sentimentos são mais importantes que as dos outros ou pensar apenas no que se quer no imediato, sem ponderar as consequências desse comportamento no futuro, para si e/ou para os outros;

- Minimizar e Etiquetar - Pensar que a sua conduta não está mal, minimizando os danos que provocam em si próprio e nos outros. Ou etiquetar os outros 
de modo a justificar o comportamento de forma que pareça justificável fazer mal a essas pessoas;

- Assumir o pior - Pensar que tudo é feito contra si próprio. Ou pensar que apenas coisas más podem acontecer e/ou que nada é possível fazer para melhorar o mal que acontece na vida;

- Culpar os outros - Não assumir a responsabilidade pelo seu comportamento, em vez disso, culpar os outros. Ou considerar que pode magoar os outros porque eles merecem ou ainda desculpabilizar o seu comportamento porque estava sob o efeito do álcool ou de substâncias psicoativas ou que foram os outros que o convenceram a consumir.

Estas distorções cognitivas justificam e facilitam o comportamento agressivo, inibindo a empatia e podendo também assumir a forma de racionalizações para justificar comportamentos de consumo de substâncias psicoativas.

Barriga et al. (2008) afirmam que a adaptação desta tipologia de distorções cognitivas ao consumo de substâncias psicoativas na adolescência é útil. As atitudes de centração no eu relacionadas com as substâncias psicoativas assumiriam a forma de «eu posso ficar eufórico quando e onde eu quiser». As racionalizações de culpar os outros consistem em atribuir o consumo de substâncias psicoativas à pressão do grupo de pares ou mesmo às próprias substâncias por serem tão altamente viciantes. As tendências para minimizar e etiquetar envolvem a perceção do consumo de substâncias psicoativas como algo inofensivo, aceitável ou até mesmo admirável e sem consequências para a saúde. E assumir o pior consiste em acreditar que as substâncias psicoativas não podem ser evitadas porque toda a gente consome.

Deste modo, a finalidade desta investigação é identificar as crenças e atitudes dos adolescentes, associadas ao uso de substâncias psicoativas, nomeadamente o uso de álcool, de tabaco, de marijuana e de outras substâncias psicoativas ilegais. De acordo com esta finalidade, pretende-se alcançar os seguintes objetivos específicos:

- Identificar quais as substâncias psicoativas mais consumidas pelos estudantes do ensino superior, o grau em que são consumidas e o tipo de crenças irracionais ou distorções cognitivas associadas aos consumos;

- Identificar quais os diferentes tipos de substâncias psicoativas consumidas pelos jovens em função do sexo e da escola que frequentam;

- Verificar se existe associação entre distorções cognitivas (centração no eu, culpar os outros e assumir o pior e minimizar e etiquetar) e o consumo das substâncias psicoativas em estudo. 


\section{METODOLOGIA}

\section{Participantes}

A amostra é constituída por 193 jovens estudantes do $1 .^{\circ}$ ano do ensino superior, 68 são do sexo masculino e 125 são do sexo feminino, o que corresponde a $35.2 \%$ de rapazes e a $64.8 \%$ de raparigas. A idade dos participantes oscila entre os 18 anos e os 25 anos. A média de idades é de 20.15 anos, a mediana é de 20 anos, a moda é de 19 anos e o desvio padrão corresponde a 1.96.

A amostra foi escolhida por conveniência entre os estudantes que frequentavam uma das três escolas do Instituto Politécnico de Portalegre no ano 2013/2014, a saber: a Escola Superior de Educação de Portalegre (55 estudantes, dos quais seis do sexo masculino e 49 do sexo feminino), a Escola Superior de Tecnologia e Gestão de Portalegre (88 estudantes, 55 do sexo masculino e 33 do sexo feminino) e a Escola Superior de Saúde de Portalegre (50 estudantes, sete do sexo masculino e 43 do sexo feminino).

\section{Instrumento}

Foi utilizado o questionário de Barriga e colaboradores (2008), o How I think about drugs and alcool questionnaire - HIT-D\&A - que inclui 52 itens para medir os comportamentos e as atitudes dos jovens relativamente ao uso de várias substâncias psicoativas tais como álcool, nicotina, marijuana, e outras substâncias ilegais. O questionário fornece também informações sobre o grau de utilização dessas substâncias, desde o consumo ocasional até ao consumo excessivo e aos sintomas de dependência. O HIT-D\&A permite ainda compreender como é que os adolescentes racionalizam o consumo de substâncias psicoativas através de distorções cognitivas, como a centração no eu, a culpabilização dos outros e a assunção do pior e ainda a desvalorização, etiquetagem e minimização do dano. Para tal, o questionário prevê a avaliação normativa de dez substâncias psicoativas comuns, está dividido em várias subescalas que se complementam: quatro relativas ao consumo de várias substâncias (álcool, nicotina, marijuana, e outras substâncias psicoativas ilegais tais como medicamentos prescritos, tabaco de mascar, alucinogénios, speed, cocaína, substâncias sintéticas e heroína), quatro relativas ao grau de utilização das referidas substâncias psicoativas (experimentação, consumo regular, consumo excessivo e dependência) e três relativas aos tipos de distorções cognitivas atrás referidos. Para cada item os jovens respondem numa escala do tipo Likert que oscila da alternativa 
discordo totalmente (1) a concordo totalmente (6), permitindo que cada jovem responda da forma mais adequada ao seu caso, em cada item.

Analisou-se a fidelidade do instrumento com o coeficiente alfa de Cronbach e o valor obtido para a escala total foi de .89 , revelando assim uma boa consistência interna, logo uma elevada fidelidade. Os alfas para as subescalas de consumo do álcool, nicotina, marijuana e outras substâncias ilegais foram respetivamente: .71, .66, .76 e .46. Dado que o valor obtido para a subescala das substâncias ilegais é muito baixo deverá considerar-se a sua eliminação em estudos futuros, se estes valores se mantiverem com amostras maiores. No que respeita às distorções cognitivas os alfas foram .70 para a centração no eu, .57 para a culpabilização dos outros e assunção do pior, e .70 para etiquetagem e minimização do dano. O valor obtido para a subescala relativa à culpabilização dos outros é baixo pelo que deverá também considerar-se a sua eliminação em estudos futuros, se esta tendência persistir com amostras maiores. Assim, neste estudo os resultados relativos ao consumo de substâncias ilícitas e os dados obtidos com a escala de culpabilização do outro/assunção do pior deverão ser encarados com reservas.

Para além dos 52 itens de avaliação do questionário, optou-se por acrescentar mais dois itens, perfazendo um total de 54 itens. Estes dois itens adicionados são relativos às novas substâncias psicoativas (NSP), também conhecidas como smartdrugs, tendo em conta o seu repentino aparecimento e a sua divulgação por parte dos meios de comunicação social. Por isso, de acordo com Calado (2013), no final de 2012 foi adotada em Portugal a designação de novas substâncias tal como se passou em outros países europeus. De acordo com a Comunidade Europeia, em 2005, novas substâncias psicoativas são drogas que não constam das tabelas das Convenções das Nações Unidas mas que podem constituir uma ameaça para a saúde pública comparável às drogas ilícitas (King \& Kicman, 2011, citados em Calado, 2013). No relatório das Nações Unidas sobre as drogas no mundo esta definição também foi adotada (UNODC, 2013), bem como pelo Ministério da Saúde de Portugal (2013).

Barriga e colaboradores (2008) apresentam normas no manual de utilização do questionário que indicam quais os scores individuais obtidos no questionário que são indicativos de consumo nas quatro etapas consideradas (experimentação, consumo regular, consumo excessivo e dependência), permitindo assim situar cada indivíduo que responde ao questionário e determinar o seu grau de risco no consumo das várias substâncias psicoativas avaliadas pelo questionário.

\section{Procedimento}

Após ser concedida a autorização dos diretores das escolas envolvidas, procedeu-se à aplicação do questionário em contexto de sala de aula. Antes da distribuição dos 
questionários foi efetuada uma breve apresentação do estudo, foram esclarecidas eventuais dúvidas e foi garantida a confidencialidade e o anonimato das respostas.

As informações recolhidas foram sujeitas a tratamento e análise estatística descritiva e inferencial através do programa informático IBM Corp. Released 2011. IBM SPSS Statistics for Windows, Version 20.0. Armonk, NY: IBM Corp.

\section{APRESENTAÇÃO DE RESULTADOS}

O gráfico 1 apresenta as frequências relativas ao consumo das diversas substâncias psicoativas que os estudantes admitiram ter experimentado.
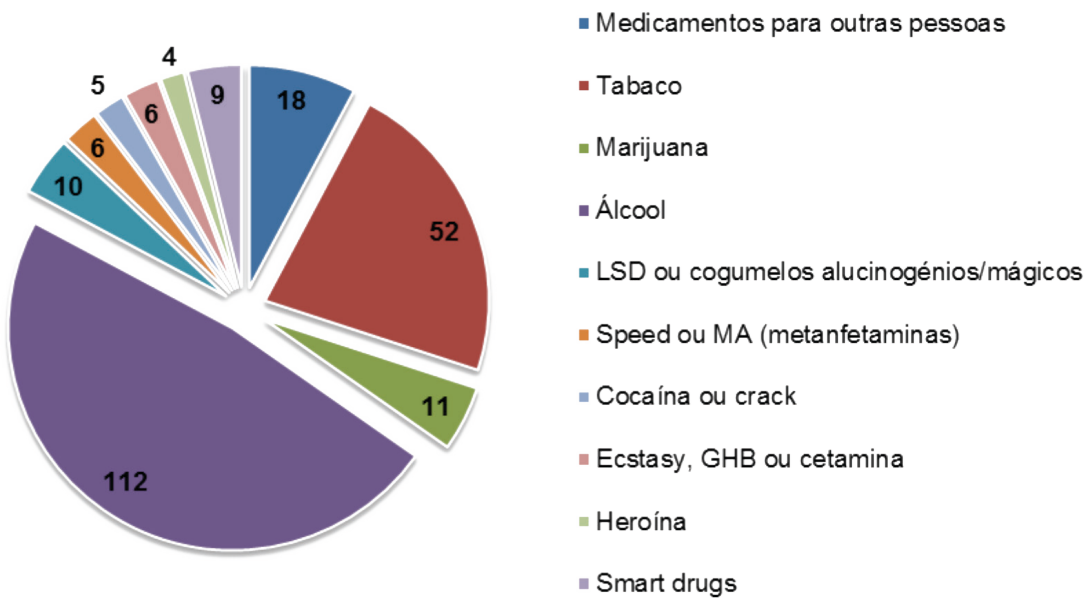

Gráfico 1. Substâncias psicoativas que os estudantes consomem.

A análise do gráfico 1 informa que 18 estudantes já tomaram medicamentos prescritos a outras pessoas. No que se refere ao tabaco, 52 estudantes afirmam que fumam cigarros, o que equivale a $26.9 \%$ do total. Já em relação ao consumo de marijuana, 11 estudantes (5.7\%) admitiram consumir essa substância. Em relação ao álcool 112 estudantes afirmam que consomem bebidas alcoólicas, o que representa $58.0 \%$ do total. Os dados mostram também que 10 estudantes (5.2\%) já consumiram LSD ou cogumelos alucinogénios/mágicos. Quanto ao consumo de speed ou $M A$ (metanfetamina) e de ecstasy, GHB ou cetamina, os dados apurados revelam que seis estudantes $(3.1 \%)$ assumem que já consumiram tais substâncias. No que 
se refere à cocaína ou crack, cinco estudantes (2.6\%) afirmam já ter consumido e quatro estudantes $(2.1 \%)$ assumem ter consumido heroína. No que respeita às smartdrugs, nove estudantes afirmam que já consumiram estas novas substâncias psicoativas, o que corresponde a 4.7\% do total dos 193 estudantes inquiridos. Este valor é mais baixo do que o apresentado no estudo de Ribeiro e colaboradores (2013), citados em Calado (2013), que revela que entre estudantes das universidades de Lisboa ( $\mathrm{N}=500$ ) 29\% dos inquiridos já tinha consumido NSP alguma vez na vida.

Como se pode constatar através da leitura do gráfico 1, a maior percentagem de consumos relativos a substâncias psicoativas feitos pelos estudantes é a relativa ao álcool. O tabaco aparece como a segunda substância psicoativa mais consumida entre os estudantes, seguindo-se o consumo de medicamentos prescritos a outras pessoas. Logo em seguida surgem os consumos de marijuana, LSD ou cogumelos alucinogénios/mágicos e de smartdrugs, com percentagens muito semelhantes. As restantes substâncias psicoativas aparecem como as substâncias menos consumidas pelos estudantes. No entanto, parece-nos que não deixa de ser um facto preocupante existir entre $3.1 \%$ e $2.1 \%$ do total dos estudantes que assume já ter consumido substâncias como ecstasy, speed, cocaína ou heroína. Este estudo revelou ainda que 106 estudantes $(55.0 \%$ do total) responderam que a maioria dos seus amigos consome álcool ou substâncias psicoativas. Os valores encontrados são próximos dos encontrados por Barriga e colaboradores (2008) com amostras normativas.

No que se refere ao tipo de substâncias psicoativas consumidas e ao grau em que são consumidas, os dados das tabelas 1 e 2 indicam que os rapazes consomem mais substâncias psicoativas e que o fazem de forma mais continuada e regular do que as raparigas, exceto para o tabaco em que a média do sexo feminino é superior à do sexo masculino.

Tabela 1

Consumo de Substâncias Psicoativas em Função do Sexo

\begin{tabular}{|c|c|c|c|c|c|c|}
\hline & Sexo & $\mathrm{N}$ & M & $\mathrm{DP}$ & Min. & Max. \\
\hline \multirow{2}{*}{ Álcool } & Masculino & 68 & 20.62 & 6.06 & \multirow{2}{*}{6} & \multirow{2}{*}{36} \\
\hline & Feminino & 125 & 19.14 & 4.84 & & \\
\hline \multirow{2}{*}{ Nicotina } & Masculino & 68 & 12.18 & 3.86 & \multirow{2}{*}{6} & \multirow{2}{*}{36} \\
\hline & Feminino & 125 & 13.30 & 4.44 & & \\
\hline \multirow{2}{*}{ Marijuana* } & Masculino & 68 & $19.81^{\star}$ & 7.61 & \multirow{2}{*}{7} & \multirow{2}{*}{42} \\
\hline & Feminino & 125 & 16.71 & 5.16 & & \\
\hline \multirow{2}{*}{$\begin{array}{l}\text { Outras substâncias psicoativas ilegais } \\
\text { (cocaína, LSD, heroína e ecstasy) }\end{array}$} & Masculino & 68 & 14.51 & 4.04 & \multirow{2}{*}{5} & \multirow{2}{*}{30} \\
\hline & Feminino & 125 & 13.80 & 3.59 & & \\
\hline \multirow{2}{*}{ Escala total ${ }^{*}$} & Masculino & 68 & $143.57^{\star}$ & 30.77 & \multirow{2}{*}{54} & \multirow{2}{*}{324} \\
\hline & Feminino & 125 & 129.38 & 22.09 & & \\
\hline
\end{tabular}

${ }^{*} p<.05$ 
Tabela 2

Grau de Consumo de Substâncias Psicoativas em Função do Sexo

\begin{tabular}{ccccccc}
\hline & Sexo & $\mathrm{N}$ & $\mathrm{M}$ & $\mathrm{DP}$ & Min. & Máx. \\
\hline \multirow{2}{*}{ Experimentação* $^{*}$} & Masculino & 68 & $9.13^{*}$ & 3.63 & 3 & 9 \\
& Feminino & 125 & 7.97 & 3.16 & & \\
Consumo regular & Masculino & 68 & $7.07^{*}$ & 4.60 & 5 & 25 \\
& Feminino & 125 & 5.75 & 2.06 & & \\
Consumo excessivo* & Masculino & 68 & $14.86^{*}$ & 4.94 & \multirow{2}{*}{6} & 36 \\
& Feminino & 125 & 11.69 & 3.44 & & \\
Comportamento aditivo* $^{*}$ & Masculino & 68 & $12.65^{*}$ & 5.29 & \multirow{2}{*}{6} & 36 \\
& Feminino & 125 & 9.99 & 4.21 & & \\
\hline
\end{tabular}

${ }^{\star} p<.05$

O estudo das diferenças entre sexos foi realizado com o $t$ de student para amostras independentes, os resultados revelaram que para a escala total: $t(103.32)=3.34$, $p<.05$, logo essas diferenças são significativas a um nível de significância de .05, no sentido de que os rapazes consomem mais substâncias (n1 = 67; $M=143.57$; $D P$ $=30.77)$ do que as raparigas $(\mathrm{n} 2=125 ; \mathrm{M}=129.38$; $\mathrm{DP}=22.09)$ e justificam mais esses consumos. Como o teste de Levene não validou a homogeneidade de variâncias $(F=8.94 ; p<.05)(F=8.94 ; p<.05)$ recorreu-se ao cálculo do tamanho do efeito (TDE) baseado na medida Delta de Glass (pertencente à família $d$ de Cohen) definida pela seguinte expressão

$$
\Delta=\frac{\bar{X}_{1}-\bar{X}_{\mathbf{2}}}{\sqrt{S_{\mathbf{2}}^{2}}}
$$

onde $\bar{X}_{1}$ e $\bar{X}_{2}$ representam as médias do grupo experimental e do grupo de controlo, respetivamente; $S_{\mathbf{2}}^{\mathbf{2}}$ representa a variância amostral do grupo de controlo (tendo-se definido, nos cálculos do TDE, como grupo experimental o grupo que apresentava a média mais elevada).

O resultado do índice Delta de Glass é, para esta situação, igual a 0.64. De acordo com a classificação de Cohen (1988), citado em Espírito Santo e Daniel (2015), pode considerar-se que a magnitude da diferença entre as médias dos dois grupos é média $(0.50 \leq \mathrm{TDE} \leq 0.79)$.

No que respeita ao consumo de álcool, verifica-se que $t(114.05)=1.73, p=.09$. Pelo resultado do teste, pode concluir-se que não existem diferenças significativas face ao consumo de álcool entre rapazes $(n 1=68 ; M=20.62 ; D P=6.06)$ e raparigas (n2 = 125; $M=19.14 ; D P=4.84$ ) para um nível de significância igual a 5\%. Também, nesta situação, como não se confirma a homogeneidade de variâncias $(F=6.30 ; p$ 
$<$.05), recorreu-se ao cálculo do TDE através do Delta de Glass que apresenta um resultado igual a 0.31 , considerando-se, assim, que a magnitude da diferença entre as médias dos dois grupos em questão é pequena $(0.20 \leq T D E \leq 0.49)$.

Para a nicotina verificou-se então que $t(191)=-1.76, p=.08$, logo as diferenças entre rapazes $(\mathrm{n} 1=68 ; M=12.18 ; D P=3.86)$ e raparigas $(\mathrm{n} 2=125 ; M=13.30 ; D P=4.44)$ não são estatisticamente significativas, no que se refere ao uso da nicotina. O cálculo do TDE para a diferença entre sexos relativamente ao uso da nicotina recorrendo à medida $d$ de Cohen (obtida através da conversão do teste $t$ ) definida pela expressão

$$
d=\frac{t\left(n_{1}+n_{2}\right)}{\sqrt{g l} \sqrt{n_{1} n_{2}}}
$$

onde $t$ representa o valor da estatística do teste $t$ de Student; $g l$ representa os graus de liberdade usados no teste $t$; n1 e n2 representam as dimensões do grupo experimental e do grupo de controlo, respetivamente.

Esta medida apresentou um resultado igual a 0.27 revelando que a magnitude de diferença entre as médias de rapazes e raparigas relativamente ao consumo de nicotina é pequena.

No que se refere ao uso de marijuana o resultado do teste $t$ para amostras independentes mostrou que $t(101.28)=3.00, p<.05$, logo as diferenças relativas ao uso de marijuana nos dois sexos são significativas, no sentido do sexo masculino admitir consumir mais marijuana $(\mathrm{n} 1=68 ; M=19.81 ; D P=5.16)$ (do que as estudantes do sexo feminino (n2 $=125 ; M=16.71 ; D P=5.16)$. A homogeneidade de variâncias não se confirma $(F=17.58 ; p<.05)$, tendo a medida Delta de Glass apresentado um resultado igual a 0.60 . Pode considerar-se que a magnitude da diferença entre as médias dos dois grupos relativamente ao consumo de marijuana é média.

Foi ainda efetuado o teste $t$ para amostras independentes para averiguar diferenças entre jovens do sexo masculino e do sexo feminino face ao consumo de outras substâncias psicoativas ilegais (cocaína, $L S D$, heroína e ecstasy), que revelou que $t(191)=1.26, p=.21$, o que significa que as diferenças no consumo dessas substâncias entre rapazes $(\mathrm{n} 1=68 ; M=14.51 ; D P=4.04)$ e raparigas $(\mathrm{n} 2=125$; $M=13.80 ; D P=3.59)$ não são significativas ao nível de .05 . O cálculo do TDE para a diferença entre sexos relativamente ao consumo de substâncias psicoativas ilegais recorrendo à medida $d$ de Cohen apresentou um resultado igual a 0.19 concluindo-se, assim, que a magnitude de diferença entre as médias é bastante pequena (quase insignificante).

No que respeita às diferenças entre sexos no grau de consumo das diferentes substâncias psicoativas, a aplicação do teste $t$ para amostras independentes revelou que $t(191)=2.32, p<.05$. Pode concluir-se que estamos perante diferenças de 
médias estatisticamente significativas entre sexos no que respeita à experimentação de substâncias psicoativas, no sentido de os rapazes efetuarem mais experiências (n1 $=68 ; M=9.13 ; D P=3.63)$ do que as raparigas (n $2=125 ; M=7.97 ; D P=3.16$ ). $\mathrm{O}$ TDE para a diferença entre sexos relativamente à experimentação de substâncias psicoativas recorrendo à medida $d$ de Cohen apresentou um resultado igual a 0.35 concluindo-se que a magnitude de diferença entre as médias é pequena.

Para o consumo regular de substâncias psicoativas, os dados apurados através da utilização do teste $t$ para amostras independentes revelaram que $t(81.89)=$ $2.25, p<.05$. Este resultado demonstra que as diferenças são significativas para o consumo regular de substâncias psicoativas, no sentido de os rapazes efetuarem mais consumos regulares $(\mathrm{n} 1=68 ; M=7.07 ; \mathrm{DP}=4.60)$ do que as raparigas $(\mathrm{n} 2=$ 125; $M=5: 75 ; D P 2.06$ ). Como o teste de Levene não validou a homogeneidade de variâncias $(\mathrm{F}=26.26 ; \mathrm{p}<.05)$ recorreu-se ao cálculo do TDE com base na medida Delta de Glass cujo resultado é, para esta situação, igual a 0.64. Pode considerar-se que a magnitude da diferença entre as médias dos dois grupos em estudo é média.

No que se refere ao consumo excessivo de substâncias psicoativas, a utilização do teste $t$ para amostras independentes mostrou que $t(101.14)=4.69, p<.05$, isto é, revela que as diferenças entre sexos face ao consumo excessivo de substâncias psicoativas são estatisticamente significativas, ou seja, os rapazes consomem com mais excesso $(\mathrm{n} 1=67 ; M=14.87 ; \mathrm{DP}=4.94)$ comparativamente às raparigas $(\mathrm{n} 2=125$; $M=11.69 ; D P=3.44)$. A homogeneidade de variâncias não se confirma $(\mathrm{F}=116-16$; $p<.05)$, tendo a medida Delta de Glass apresentado um resultado igual a 0.92 . Pode considerar-se que a magnitude da diferença entre as médias de rapazes e raparigas face ao consumo excessivo de substâncias psicoativas é grande $(0.80 \leq T D E \leq 1.29)$.

Já em relação à dependência de substâncias psicoativas, o resultado do teste $t$ para amostras independentes revelou que $t(113.79)=3.57, p<.05$, logo pode afirmar-se que há diferenças estatisticamente significativas entre sexos na dependência de substâncias psicoativas, na medida em que os rapazes exibem mais comportamentos de dependência ( $\mathrm{n} 1=68 ; M=12.65 ; D P=5.29)$ em comparação com as raparigas (n2 = 125; $M=9.99 ; D P=4.21$ ). Não se confirmando a homogeneidade de variâncias $(F=7.26 ; p<.05)$, recorreu-se ao Delta de Glass no cálculo do TDE, que apresentou um resultado igual a 0.63 permitindo concluir que a magnitude da diferença entre as médias de rapazes e raparigas face à dependência de substâncias psicoativas é média.

Em suma, os rapazes além de consumirem mais substâncias psicoativas exibem também um padrão de consumo de substâncias mais frequente e regular que as raparigas.

A tabela 3 apresenta as médias na escala total obtidas pelos estudantes das três escolas que participaram neste estudo. O valor mais elevado foi o da Escola Superior de Tecnologia e Gestão, seguido da Escola Superior de Saúde e por fim da Escola Superior de Educação. A fim de se verificar se as diferenças entre esco- 
las eram estatisticamente significativas, foi aplicado o teste estatístico ANOVA, seguido de um teste Tukey de comparações múltiplas, que permite discriminar que diferenças entre as três escolas analisadas são significativas. Os resultados obtidos indicam que F $(2.189)=5.49, p<.05$. Assim, pode concluir-se que existem diferenças estatisticamente significativas entre as três escolas analisadas. Para avaliar o efeito na ANOVA (One-Way) recorreu-se ao índice Eta Square definido pela seguinte expressão:

$$
\eta^{\mathbf{2}}=\frac{\text { SS Between }}{\text { SS Total }}
$$

que Cohen converteu na seguinte expressão alternativa:

$$
f=\sqrt{\frac{\eta^{2}}{1-\eta^{2}}}
$$

$\mathrm{Na}$ situação referente ao teste de diferenças de médias entre os estudantes das três escolas verificou-se que $f=.24$, o que se traduz, de acordo com a classificação sugerida por Cohen, num efeito pequeno. $\mathrm{O}$ valor $\mathrm{h}^{2} .055$ significa que apenas 5.5\% da variância na escala total se pode atribuir ao efeito das escolas frequentadas pelos estudantes.

O teste Tukey de comparações múltiplas indicou que apenas eram estatisticamente significativas as diferenças entre a Escola Superior de Tecnologia e Gestão e as restantes escolas. Como essa escola é mais frequentada por rapazes do que as outras duas, esta diferença dever-se-á provavelmente mais às diferenças de sexo encontradas nos consumos do que ao contexto escolar propriamente dito.

Para avaliar a magnitude dos efeitos introduzidos pelas três Escolas na comparação de pares de médias recorreu-se à seguinte medida adaptada do $d$ de Cohen:

$$
d=\frac{\bar{X}_{\mathbf{1}}-\bar{X}_{\mathbf{2}}}{\sqrt{M S \text { Within }}}
$$

O valor da magnitude da diferença entre as médias da Escola Superior de Tecnologia e Gestão e da Escola Superior de Educação é igual a 0.51 revelando um efeito médio; a magnitude da diferença entre as médias da Escola Superior de Tecnologia e Gestão e da Escola Superior de Saúde é igual a 0.44 traduzindo-se num efeito pequeno e, finalmente a diferença entre as médias da Escola Superior de Saúde e da Escola Superior de Educação apresenta uma magnitude com um valor igual a 0.07 (efeito insignificante). 
Tabela 3

Diferenças entre Médias nas Três Escolas do IPP

\begin{tabular}{cccc}
\hline & $\mathrm{N}$ & $\mathrm{M}$ & $\mathrm{DP}$ \\
\hline $\begin{array}{c}\text { Escola Superior de } \\
\text { Educação }\end{array}$ & 55 & 127.93 & 22.85 \\
$\begin{array}{c}\text { Escola Superior de } \\
\text { Tecnologia e Gestão* }\end{array}$ & 87 & $141.03^{*}$ & 29.86 \\
Escola Superior de Saúde & 50 & 129.70 & 20.04 \\
Total & 192 & 134.33 & 26.27 \\
\hline
\end{tabular}

${ }^{*} p<.05$

Finalmente efetuaram-se correlações de Pearson entre as subescalas referentes aos quatro tipos de substâncias psicoativas estudados e as subescalas relativas aos três tipos de distorções cognitivas referenciados. As correlações obtidas foram positivas, elevadas e estatisticamente significativas, indicando uma associação forte entre os consumos das várias substâncias psicoativas e as três distorções cognitivas. As correlações foram particularmente elevadas entre a distorção cognitiva de centração no eu e os quatro tipos de substâncias psicoativas ilegais. A correlação entre o álcool e as outras substâncias foi razoável sobretudo com a marijuana e outras substâncias ilegais.

Tabela 4

Correlações (Pearson) dos Diferentes Tipos de Substâncias Psicoativas, Distorções Cognitivas, Escala dos Comportamentos e Escala das Atitudes

\begin{tabular}{|c|c|c|c|c|c|c|c|c|c|c|}
\hline & & 1 & 2 & 3 & 4 & 5 & 6 & 7 & 8 & 9 \\
\hline 1 & Álcool & - & & & & & & & & \\
\hline 2 & Nicotina & $.395^{\star}$ & - & & & & & & & \\
\hline 3 & Marijuana & $.478^{\star}$ & $.290^{*}$ & - & & & & & & \\
\hline 4 & $\begin{array}{l}\text { Outras substâncias psi- } \\
\text { coativas ilegais (cocaína, } \\
\text { LSD, heroína e ecstasy) }\end{array}$ & $.480^{*}$ & $.273^{*}$ & $.575^{\star}$ & - & & & & & \\
\hline 5 & Centração no eu & $.686^{*}$ & $.507^{\star}$ & $.684^{*}$ & $.707^{\star}$ & - & & & & \\
\hline 6 & $\begin{array}{l}\text { Culpar os outros e } \\
\text { assumir o pior }\end{array}$ & $.674^{*}$ & $.616^{*}$ & $.652^{\star}$ & $.586^{*}$ & $.562^{\star}$ & - & & & \\
\hline 7 & Minimizar e etiquetar & $.682^{*}$ & $.474^{\star}$ & $.780^{\star}$ & $.615^{\star}$ & $.613^{*}$ & $.624^{*}$ & - & & \\
\hline 8 & $\begin{array}{c}\text { Escala dos } \\
\text { comportamentos }\end{array}$ & $.503^{*}$ & $.341^{\star}$ & $.562^{\star}$ & $.444^{*}$ & $.443^{*}$ & $.539^{*}$ & $.641^{\star}$ & - & \\
\hline 9 & Escala das atitudes & $.795^{\star}$ & $.620^{*}$ & $.823^{\star}$ & $.746^{\star}$ & $.859^{\star}$ & $.842^{*}$ & $.866^{*}$ & $.628^{\star}$ & - \\
\hline
\end{tabular}


Em suma, as distorções cognitivas, crenças irracionais ou erros de pensamento, surgem associadas à justificação da experimentação e da continuidade de consumos de substâncias psicoativas, embora a maioria dos estudantes saiba que são nocivas para a saúde.

Efetuaram-se ainda comparações entre os percentis obtidos no presente estudo e as normas propostas por Barriga e colaboradores (2008) para determinar quais os valores na escala que colocam cada indivíduo numa das quatro etapas dos consumos, e por consequência em risco de dependência. Verificou-se que $20 \%$ da amostra do presente estudo se situava em risco de dependência do álcool, um valor elevado. Nas restantes substâncias psicoativas os valores da amostra em estudo nunca atingiram os níveis de risco de dependência, ou seja, os valores mais elevados encontrados pelos referidos autores.

\section{DISCUSSÃO E CONCLUSÕES}

A análise dos resultados permite concluir que o questionário HIT-D\&A de Barriga e colaboradores (2008) possui razoáveis propriedades psicométricas e poderá ser útil quer para a avaliação de programas de prevenção do consumo de substâncias psicoativas dirigidos a grupos de jovens, quer para avaliação clínica de casos individuais.

Em relação ao número de estudantes que assume que já consumiu diversas substâncias psicoativas, verifica-se que a maior percentagem de consumos feitos pelos estudantes é relativa ao álcool, tal como sucede em outros estudos com estudantes universitários portugueses (Alcantara et al., 2015) e com estudantes universitários brasileiros (Zeferino et al., 2015). O tabaco aparece como a segunda substância psicoativa mais consumida entre os jovens, seguindo-se o consumo de medicamentos prescritos a outras pessoas. Logo em seguida surgem os consumos de marijuana, LSD ou cogumelos alucinogénios/mágicos e de smartdrugs, com percentagens muito semelhantes. As restantes substâncias psicoativas (ecstasy, $G H B$ e cetamina, cocaína ou crack, speed ou $M A$ e heroína) aparecem como as substâncias menos consumidas pelos estudantes. No entanto, não deixa de ser um facto preocupante haver entre $3.1 \%$ e $2.1 \%$ do total dos estudantes que assume já ter consumido substâncias como ecstasy, speed, cocaína ou heroína, dado este que é congruente com os resultados obtidos por Alcantara e colaboradores (2015) com estudantes da Universidade de Lisboa.

A amostra do presente estudo não apresentou valores indicativos de dependência na maioria das substâncias (quando comparados os percentis da amostra com 
os dos autores da escala), à exceção dos valores do álcool, em relação ao qual se verificou que $20 \%$ da amostra apresentava risco de dependência, um valor elevado e preocupante, contudo coerente com outros estudos que sugerem uma relação entre as festas e praxes académicas no ensino superior e o consumo excessivo de bebidas alcoólicas (Alcantara et al., 2015; Cabral, 2007).

Outra conclusão que ressalta neste estudo é a existência de diferenças significativas entre os dois sexos. Assim, conclui-se que o sexo masculino consome mais substâncias psicoativas (no caso da marijuana as diferenças são estatisticamente significativas) do que o sexo feminino, com a exceção da nicotina. Este resultado é coerente com os resultados obtidos no estudo de Feijão e colaboradores (2011) que concluiu que se registou um aumento expressivo na percentagem de consumidores de tabaco/nicotina nos alunos de 15 ou mais anos de idade, com aumentos ligeiramente maiores nas raparigas.

Outra conclusão decorrente da análise dos resultados tem a ver com as diferenças estatisticamente significativas entre os dois sexos relativamente ao grau de consumo de substâncias psicoativas (experimentação, consumo regular, consumo excessivo e dependência). As médias revelaram ser sempre superiores nos rapazes, nas quatro etapas encontradas no consumo de substâncias psicoativas, de uma forma estatisticamente significativa, indicando o grupo dos rapazes como estando numa situação de maior risco face ao consumo de substâncias psicoativas, este resultado é congruente com os resultados obtidos por Alcantara e colaboradores (2015) com estudantes da Universidade de Lisboa.

Quanto ao facto de se haver registado mais consumos na Escola Superior de Tecnologia e Gestão comparativamente às restantes escolas, pensamos que tal facto se deve à variável sexo e não à variável escola, tendo em conta que o número de rapazes é superior em relação ao número de raparigas nesta escola e que é também proporcionalmente superior ao de raparigas quando comparado com as outras escolas.

No que respeita às correlações, os resultados permitiram afirmar que a correlação entre o consumo de marijuana e a de outras substâncias psicoativas ilegais (cocaína, LSD, heroína e ecstasy) revelou ser elevada. Em relação ao consumo de álcool, este apresentou uma correlação moderada com o consumo de nicotina, de marijuana e de outras substâncias psicoativas ilegais (cocaína, LSD, heroína e ecstasy). Já o consumo de nicotina apresentou uma correlação baixa face ao consumo de marijuana e de outras substâncias psicoativas ilegais (cocaína, LSD, heroína e ecstasy). Estes resultados parecem indicar que o consumo de álcool e marijuana podem associar-se ou conduzir ao consumo de outras substâncias ilegais, sendo esta associação menos explícita no que concerne à nicotina, dado que é coerente com os resultados obtidos por Alcantara e colaboradores (2015) com estudantes da Universidade de Lisboa. 
Os resultados das correlações permitiram assim concluir que existe uma forte associação entre as três distorções cognitivas consideradas e os consumos das várias substâncias psicoativas, ou seja, o consumo de substâncias psicoativas está fortemente associado a crenças irracionais que remetem para formas de pensamento: demasiado centradas nas necessidades imediatas do eu (centração do eu); que desresponsabilizam o próprio e atribuem culpa aos outros (culpar os outros e assumir o pior); e que desvalorizam as consequências na saúde do consumo de substâncias psicoativas (minimizar e etiquetar) (Gibbs,1991 citado em Martins, 2009; Martins \& Vicente Castro, 2009). A subescala das atitudes/ crenças irracionais possui uma correlação elevada com o consumo de álcool, de marijuana e de outras substâncias psicoativas ilegais (cocaína, LSD, heroína e ecstasy). A centração no eu apresentou ainda uma correlação elevada com o consumo de outras substâncias psicoativas ilegais (cocaína, LSD, heroína e ecstasy). A distorção cognitiva de minimizar e etiquetar teve igualmente uma correlação elevada com o consumo de marijuana. A centração no eu foi a distorção cognitiva que apresentou as correlações mais elevadas com as diferentes substâncias psicoativas, o que sugere que os estudantes destas idades e a frequentar o primeiro ano do ensino superior manifestam ainda vestígios do "egocentrismo" adolescente. Sendo esta etapa uma fase de mudança de residência, de amigos, de maior liberdade e de novas experiências, os jovens apresentam-se vulneráveis e ainda muito centrados em experiências que lhes proporcionem prazer e divertimento imediatos, que parecem ser facilitadoras dos consumos (Alcantara et al., 2015).

Este estudo tem algumas limitações, nomeadamente a reduzida dimensão da amostra face à dimensão da escala; o facto de apenas um nível e um ano de escolaridade terem respondido ao questionário (primeiro ano do ensino superior), pelo que deverá ser encarado como um estudo exploratório. A aplicação do questionário a uma amostra maior que inclua os vários anos de escolaridade do ensino secundário e do ensino superior poderá contribuir para melhor verificar as propriedades psicométricas da escala, bem como as suas potencialidades, quer para avaliar programas de prevenção, quer para avaliar casos clínicos individuais. Em estudos futuros, poderão ainda calcular-se os percentis e as normas portuguesas no que respeita às várias etapas de consumo consideradas.

Em suma, a presente investigação sugere uma forte associação entre as crenças irracionais dos jovens do ensino superior e o consumo de diversas substâncias psicoativas. Assim, interessa prevenir comportamentos de risco, incidindo em ações que promovam a consciencialização das consequências do uso de substâncias psicoativas, ou seja, ações preventivas que alterem a relação dos jovens com as substâncias psicoativas, bem como as crenças irracionais a elas associadas, uma que vez que os modelos de Gibbs (1991) citado em Martins (2009) e de Barriga 
e colaboradores (2008) sugerem que a presença das distorções cognitivas como a centração no prazer imediato do eu, e a inibição dos mecanismos da responsabilização pelos próprios atos e de justificação de comportamentos nocivos à saúde, são facilitadoras dos consumos.

Como afirma Patrício (2006):

Podem-se considerar diversos modelos de Prevenção, centrados nas substâncias, nas pessoas, no ambiente, na redução de riscos, num modelo integrado. Mas a prevenção começa por nós, com as boas atitudes que assumimos. Ultrapassar a nossa ignorância e os mitos e utilizar uma boa educação é uma excelente forma de fazer Prevenção. Prevenir significa precaver. Percebe-se que a pessoa que recebeu conhecimento e que foi educada estará mais robusta, estará capaz de se acautelar, mais prevenida face ao consumismo, incluindo o das substâncias «droga». (p. 146)

Desta forma, julga-se que a intervenção preventiva na escola não deve passar apenas pelo desenvolvimento de ações de sensibilização sobre as substâncias psicoativas, deverá envolver toda a comunidade educativa e, sobretudo, envolver os jovens em projetos de desenvolvimento pessoal (Silva, 2010), para desenvolver as suas próprias competências na promoção de projetos promotores de estilos de vida saudáveis, favorecendo o reforço positivo das relações interpessoais, a criação de atitudes assertivas e acima de tudo, contribuir para a redução de fatores de risco, uma vez que a preocupação com a prevenção dos consumos ao nível do ensino superior continua pertinente e necessária.

\section{REFERÊNCIAS}

Alcantara, P. B., Borrego, R., Ferreira, V., Lavado, E., Melo, R. Rowland, J., \& Trunigen, M. (2015). Consumos e estilos de vida no ensino superior: $O$ caso dos estudantes da Universidade de Lisboa/2012. Serviço de intervenção nos comportamentos aditivos e nas dependências (SICAD). Observatório Permanente da Juventude/Instituto de Ciências Sociais da Universidade de Lisboa. Consultado a 9 de agosto de 2016 em http://www.sicad.pt/BK/ EstatisticaInvestigacao/EstudosConcluidos/Lists/SICAD_ESTUDOS/Attachments/154/ Monografia.pdf

Barriga, A., Gibbs, J., Potter, G., Konopisos, M., \& Barriga, K. (2008). The how I think about drugs and alcohol questionnaire. Champaign, IL: Research Press.

Cabral, L. (2007). Consumo de bebidas alcoólicas em rituais/praxes académicas (Tese de doutoramento não publicada). Universidade do Porto, Porto. Consultado a 20 de abril de 2017 em: https:// repositorio-aberto.up.pt/bitstream/10216/7207/2/Doutoramento\%20Lidia\%20do\%20Rosrio\%20 Cabral\%20Agosto2007.pdf 
Calado, V. (2013). Novas substâncias psicoativas. O caso da salvia divinorum. Lisboa: Serviço de Intervenção nos Comportamentos Aditivos e nas Dependências.

Dibiase, A, Gibbs, J., Potter, G., \& Bount, M. (2012). Teaching adolescents to think and act responsibly: The equip approach. Champaign, Illinois: Research press.

Eisenstein, E. (2005). Adolescência: Definições, conceitos e critérios. Adolescência \& Saúde 2(2), 6-7. Consultado a 30 de maio de 2014 em http://www.adolescenciaesaude.com/detalhe_artigo. asp?id=167

Espirito Santo, H., \& Daniel, F. (2015). Calcular e apresentar tamanhos do efeito em trabalhos científicos (1): As limitações do p < 0.05 na análise de diferenças de médias de dois grupos. Revista Portuguesa de Investigação Comportamental e Social.1(1), 3-16. doi: 10.7342/ismt.rpics.2015.1.1.14

Feijão, F., Lavado, E., \& Calado, V. (2011) E.C.A.T.D. 2011 - Estudo sobre o consumo de álcool, tabaco e droga, em alunos do ensino público. In SICAD - Serviço de Intervenção nos Comportamentos Aditivos e nas Dependências. Consultado a 5 de junho de 2014 em http://www.sicad.pt/PT/ EstatisticaInvestigacao/EstudosConcluidos/Paginas/detalhe.aspx?itemId=125\&lista=SICAD_ ESTUDOS\&bkUrl=/BK/EstatisticaInvestigacao/EstudosConcluidos

Gibbs, J., Potter, G., \& Goldstein, A. (1995). The Equip program: Teaching youth to think and act responsibly through a peer-helping approach. Champaign, Illinois: Research Press.

Martins, M. J. D. (2009). Maus tratos entre adolescentes na escola. Penafiel: Ed. Novembro.

Martins, M. J. D., \& Vicente Castro, F. (2007). Desenvolvimento moral e conduta antissocial: Que relações? In V. Trindade, N. Trindade, \& A. Candeias (Orgs.). Atas do congresso internacional A unicidade do conhecimento. (on-line). Évora: Universidade de Évora. Consultado em outubro de 2009 em www.ciep.uevora.pt/publicacoes/uc

Martins, M. J. D., \& Casasnovas, J. (2014). Histórias de vida de reclusos e reinserção social. International Journal of Developmental and Educational Psychology 1(1), 553-564. doi: 10.17060/ ijodaep.2014.n1.v1.403

Ministério da Educação [M.E.] (Ed.). (1988). Os Professores e a Droga: Manual Pedagógico, IV. Coleção Projeto de Vida. Lisboa: Ministério da Educação.

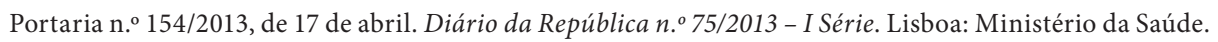
Patrício, L. (2002). Droga para que se saiba. Lisboa: Livraria Figueirinhas.

Patrício, L. (2006). Droga: Aprender para prevenir. Abrantes: Abrangráfica, Artes Gráficas e Papelaria, Lda.

Pimentel, M. H., Mata, M. A, \& Anes, E. M. (2013). Tabaco e álcool em estudantes: Mudanças decorrentes do ingresso no ensino superior. Psicologia, Saúde \& Doenças, 14(1), 185-204.

Sprinthall, N., \& Collins, W. (1994). Psicologia do adolescente: Uma abordagem desenvolvimentista. Lisboa: Fundação Calouste Gulbenkian.

Silva, A. (2004). Desenvolvimento de competências sociais nos adolescentes. Lisboa: Climepsi Editores.

UNODC (2014). World drug report. United Nations publication, Sales No. E.14.XI.7 Consultado a 23 de fevereiro de 2015 em http://www.unodc.org/documents/wdr2014/World_Drug_Report_2014_web.pdf

Zeferino, M. T., Hamilton, H., Brands, B., Wrigth, M. G., Crumbille, F., \& Fhenti, A. (2015). Consumo de drogas entre estudantes universitários: Família, espiritualidade e entretenimento moderando a influência dos pares. Texto, Contexto e Enfermagem, 24(Esp.), 125-135. doi: 10.1590/0104-07072015001150014 